\title{
Efalizumab in Psoriasis: Our Experience with 11 Patients
}

\author{
C. Rodríguez-Cerdeira ${ }^{*}, 1$, S. Díez-Moreno ${ }^{1}$, A. Molares ${ }^{1}$ and A. Guerra-Tapia ${ }^{2}$ \\ ${ }^{I}$ Department of Dermatology, Complejo Hospitalario de Vigo and Vigo University, Vigo, Spain \\ ${ }^{2}$ Department of Dermatology, Hospital 12 Octubre, Madrid, Spain
}

\begin{abstract}
This is an observational, longitudinal and retrospective study of a group of patients with moderate to severe plaque psoriasis whom had been treated with efaluzimab ( $1 \mathrm{mg} / \mathrm{Kg} /$ week) for up to 20 weeks. Nevertheless, first dose of $0.7 \mathrm{mg} / \mathrm{kg}$ was given. The efficacy of the drug was evaluated by measuring the psoriasis area and severity index (PASI), the body surface area (BSA) and index of the quality of life (DLQI).

A statically significant improvement was observed in the PASI, BSA and DLQI after 4, 12 and 20 weeks of therapy.

After 20 weeks of treatment, the PASI 75 and 90 values were $100 \%$ and $97 \%$ respectively. When it comes to safety, efaluzimab was well tolerated and no remarkable side effects were recorded.
\end{abstract}

Keywords: Efaluzimab, psoriasis, treatment, safety.

\section{INTRODUCTION}

Psoriasis is a chronic, genetically inherited, inflammatory cutaneous disease, with an immunological mechanism. The prevalence of psoriasis in Spain has been estimated to be between $1.17-1.43 \%$. Psoriasis has a great impact on the quality of life of patients, is an important public health issue and is a chronic disease requiring safe, long-term treatment. Over the latter decade, a new understanding about the pathophysiology of psoriasis has resulted in the development of a new class of agents for treating moderate to severe patients: targeted biological therapy $\mathrm{d}$, which is a humanized IgG1 monoclonal antibody which, due to its anti-D11 effect, is capable of blocking the endothelial migration and $\mathrm{T}$ cell activation on the skin, fundamental processes in the etiopathogeny of psoriasis. It is designed to be administered weekly by subcutaneous injection and may be used by patients in their own homes [1,2].

First in Europe and in 2009 in the United States, efalizumab was withdrawn from the market after 3 confirmed and 1 suspected case of progressive multifocal leukoencephalopathy (PML) were spontaneously reported.

The objective of this study is to evaluate the effectiveness and clinical safety of efalizumab for moderate and severe cases of psoriasis when the disease does not respond to commonly prescribed treatments.

\section{MATERIAL AND METHODS}

\section{Patients}

A total of 11 male patients were enrolled, with a mean of age 45 of years (range, 18-79), with moderate to severe

*Address correspondence to this author at the Department of Dermatology, CHUVI, Meixoeiro Hospital \& University of Vigo, 36200 Vigo, Spain; Tel: 0034600536114; Fax: 0034986276416;

E-mails: Carmen.Rodriguez.Cerdeira@sergas.es,

aristoteles_cerdeira@yahoo.es plaques of psoriasis, which had not responded to or were otherwise contraindicated or intolerant to other systemic or biological treatments. Topical agents were not used concomitantly.

All patients received efalizumab at a dose of $1 \mathrm{mg} / \mathrm{kg} / \mathrm{week}$. Each patient was examined at onset and on the following visits with various scales: PASI, BSA and DLQI. Before starting efalizumab, a Mantoux analytical test, and chest-X-ray study was performed on all patients, with the provision of chemoprophylaxis in the event of positive results. All the patients were found to be negative.

\section{Design}

We used an observational, longitudinal and retrospective study of one cohort of patients with psoriasis undergoing continued treatment with efalizumab. A total of eleven ambulatory patients were included in the study.

\section{Efficacy Criteria}

Drug efficacy was evaluated in terms of the PASI, BSA, physician's global assessment (PGA) and patient evaluation (PE).

The PASI assesses the degree of erythema, infiltration and desquamation of the psoriasis lesions in relation to the percentage affected topographic area scored on a scale of 0 22 (mild $<10$, moderate $10-20$ and severe $>20$ ).

The BSA in turn assesses body surface affected and classifies the severity of the condition according to clinically affected BSA. The BSA is classified as follows: mild psoriasis (affecting less than $2 \%$ of the total skin surface, moderate psoriasis $(2-10 \%)$, and severe psoriasis (over $10 \%$ of the total skin surface).

The PGA score provides a global assessment based on physician criterion from 1 to 10 points.

Finally, the PE score provides a global satisfaction index based on the patient's own criterion from 1 to 10 points. 


\section{Safety}

Safety was evaluated in all the patients included in the study, by considering the adverse events and infections.

\section{Statistic Analysis}

This was carried out using SPSS-14. A descriptive analysis of all the study variables collected was performed using mean and standard deviation for the quantitative variables and frequencies and percentages for the qualitative variables, studying the prevalence and incidence rates.

The Chi-squared test was used for association between qualitative variables.

\section{RESULTS}

\section{Patient Distribution}

The information had been gathered for 11 patients with moderate to severe psoriasis, who had been undergoing treatment with efalizumab at a dose of $1 \mathrm{mg} / \mathrm{kg} /$ week for between 4 and 20 weeks. The median age was 45 years, none of the patients showed arthritic symptoms.
$80 \%$ of the patients had obtained complete remission of the illness at twenty weeks. Prior to this continuous treatment, 3 of them had received acitretin and or photeraphy, 5 methotrexate, 3 cyclosporine, and 1 of them had received etanercept at a dose of $100 \mathrm{mg} / \mathrm{week}(50 \mathrm{mg}$ twice a week).

\section{Efficacy Analysis}

The PASI score improved significantly from week 16 onwards. After 20 weeks of therapy, PASI 75 and 90 were $100 \%$ and $80.0 \%$ respectively. The PASI basal and the weight of the patients had a graphic of similar characteristics (Fig. 1).

The BSA was seen to have decreased significantly at the end of the study from $50.0 \%$ (IQR: $30-70$ ) at the start to 5.0 \% (IQR: 4.0-11.0) after 20 weeks of treatment. BSA basal rate was proportionately to the years of treatment (Fig. 2).

The main score at baseline for dermatologic life quality index (DLQI), was 20.2\% (range: 11.0-24.5). A mean $99.0 \%$ improvement was seen at week 20 .

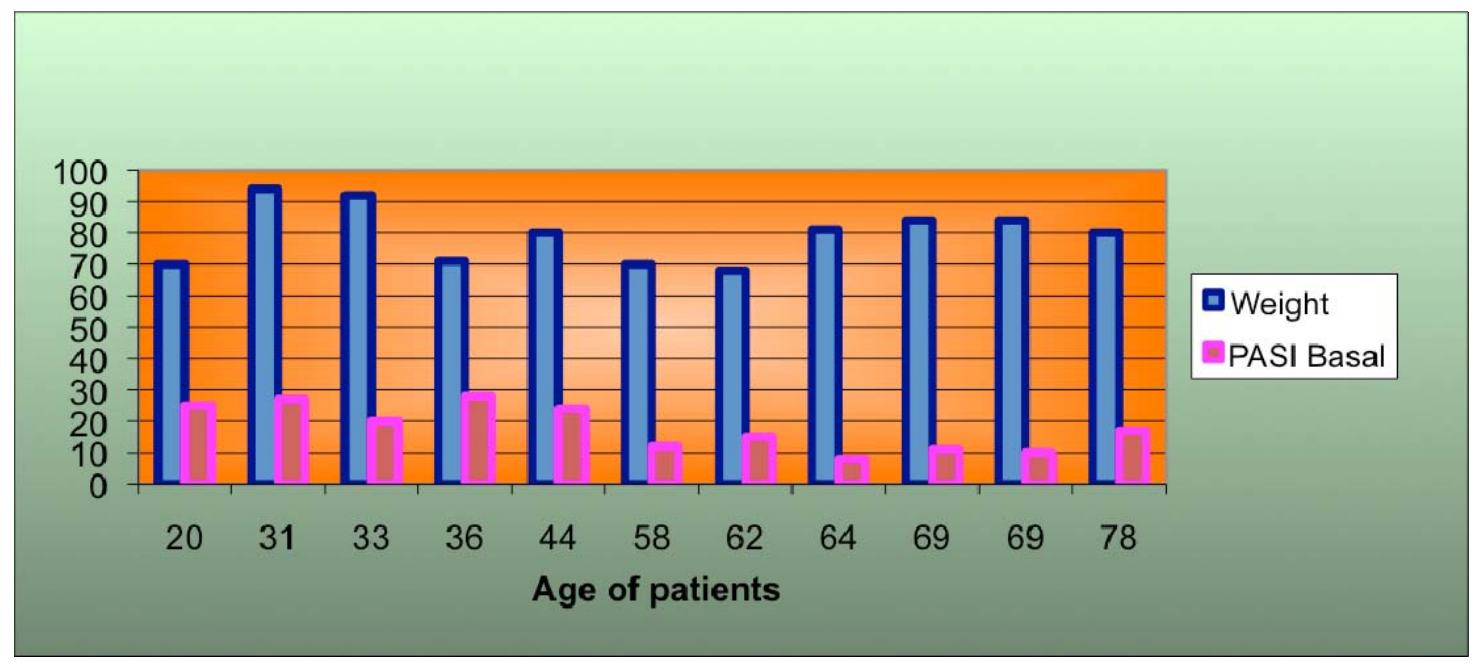

Fig. (1). Weight and PASI basal comparative. PASI: Psoriasis area and severity index.

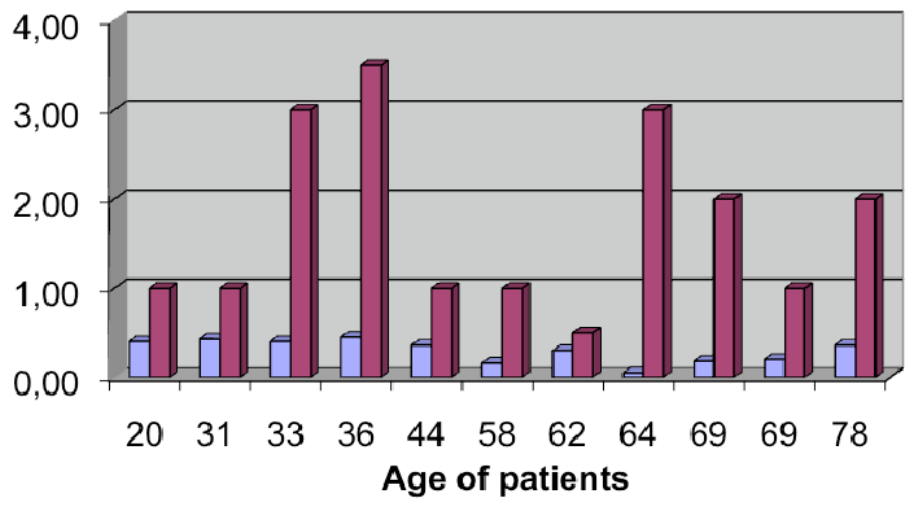

口BSA Basal

Fig. (2). BSA and YT comparative. BSA: Body surface area; YT: Years in treatment. 


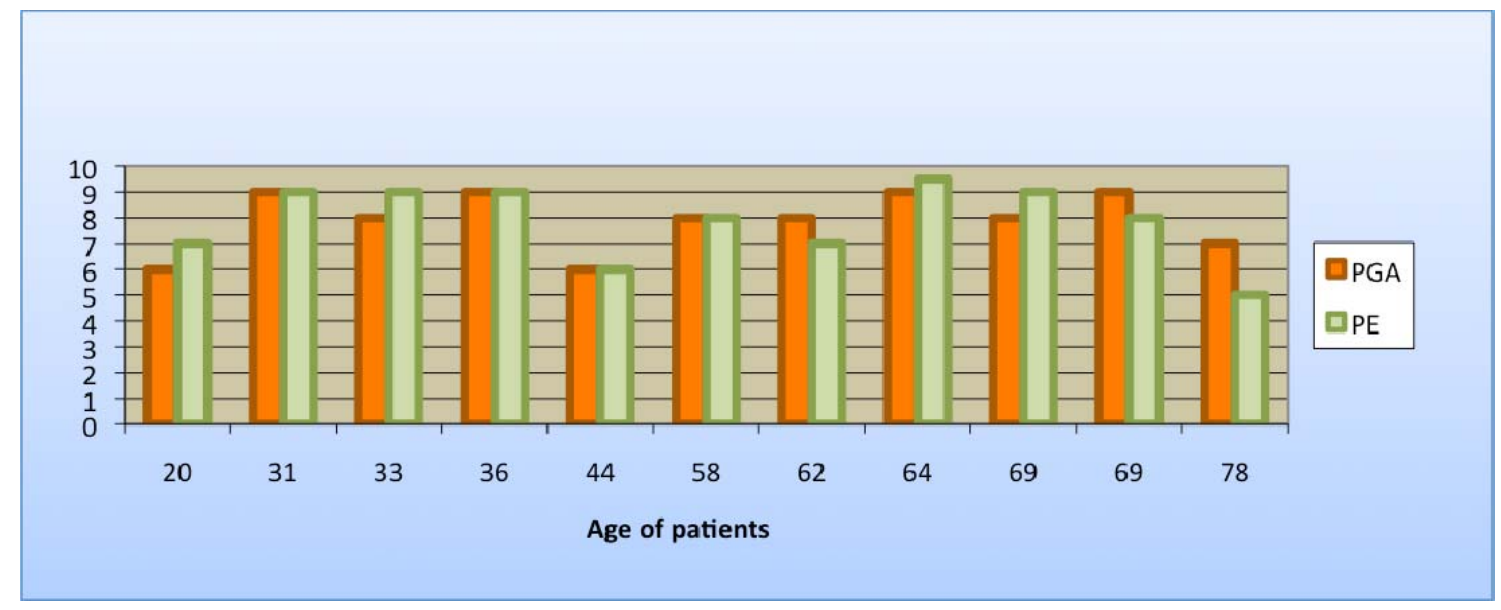

Fig. (3). PGA and PE comparative. PGA: Physician's global assessment; PE: Patients' evaluation.

\section{Safety Analysis}

Efalizumab was well tolerated by our patient population. The adverse events and infections were insignificant and no cases of tuberculosis or opportunistic infectious processes were observed during this study.

\section{DISCUSSION}

As has already been commented, efalizumab has shown its efficacy and safety over 20 weeks use in the treatment of patients with moderate to severe plaque psoriasis. Other authors have published similar results [3-5].

Regarding efficacy, our study shows statistically significant improvement in the BSA and PASI after 8 weeks of treatment. The BSA decreased significantly after treatment to $6.0 \%$ at the end of the study.

With regards to the PASI, $80 \%$ of the patients reached PASI 90 after week 20 , and $100 \%$ reached PASI 75 at this time. This coincides with others studies [5, 6] (Fig. 3).

At four weeks all patients showed important improvements.

The mean of subjective evaluation of the patient from twenty weeks of treatment was 8.75 . The PGA and PE were observed to be similar, with ratings of 9 in $56 \%$ of the patients (Figs. 4, 5).

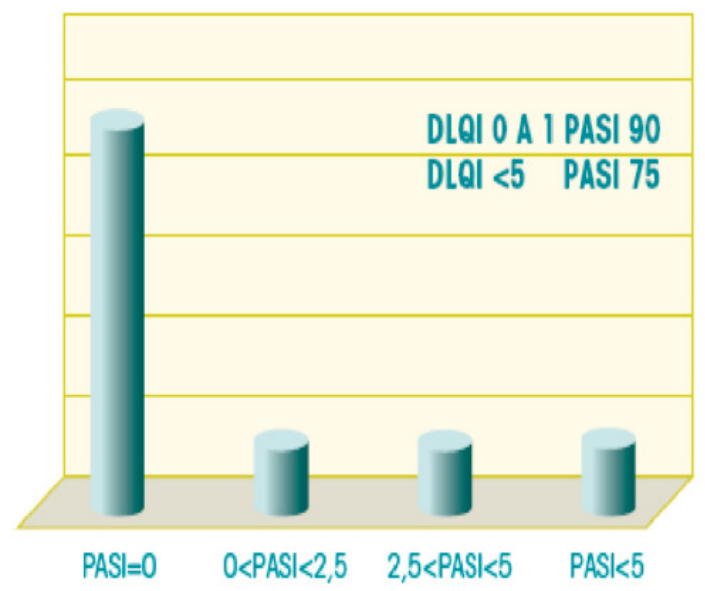

Fig. (4). Quality of life and PASI.

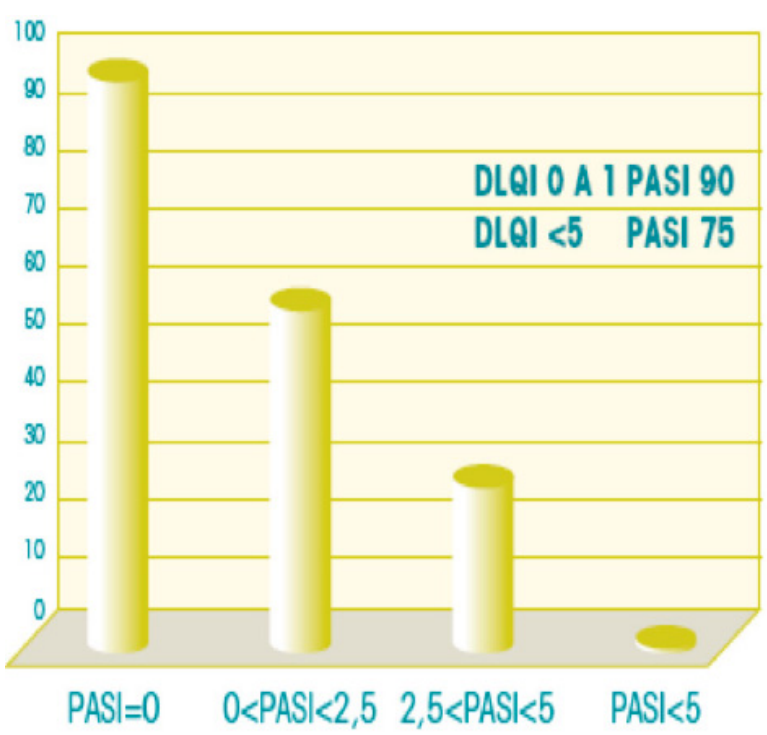

Fig. (5). The effect of efalizumab in the Quality of life and PASI.

Regarding safety, the most common adverse reactions associated with efalizumab are a complex symptom that includes headache, chills, fever, nausea, and myalgia within 48 hours following the first 2 injections. In clinical trials, these events were largely mild to moderate when a first dose of $0.7 \mathrm{mg} / \mathrm{kg}$ was given. In our experience, only, about two thirds of the patients presented dyslipemy, which was already present at the start of the study in one of them.

\section{CONCLUSIONS}

Our experience, although preliminary, shows efficacy and safety over time which endorses the employment of efalizumab in monotherapy as a therapeutic option for the treatment of the chronic psoriasis in moderated to severe plaques $[7,8]$.

The use of efalizumab must be taken into consideration in those patients whom do not respond to either conventional treatments or other previous biological treatments.

We do not find accumulation of toxicity in the patients, so efalizumab permits long-term use, better control of the psoriasis and an improvement in the quality of life in all patients [9] (Figs. 4, 5). 


\section{REFERENCES}

[1] Duber Larsen CG, Sterry W, Bos JD, et al. Clinical experience acquired with the efalizumab (Raptiva) (CLEAR) trial in patients with moderate-to-severe plaque psoriasis: results from a phase III international randomized, placebo-controlled trial. Br J Dermatol 2006; 155: 170-81.

[2] Hodulik S, Hadi S. Efalizumab: a biological agent for the treatment of psoriasis. Rev Recent Clin Trials 2006; 1: 165-8.

[3] Brimhall AK, King LN, Licciardone JC, Jacobe H, Menter A. Safety and efficacy of alefacept, efalizumab, etanercept and infliximab in treating moderate to severe psoriasis: a meta-analysis of randomized controlled trials. Br J Dermatol 2008; 159: 274-85.

[4] Lynde C. Use of biologic therapeutics in difficult-to-treat psoriasis. J Cutan Med Surg 2009; 13: 6-17.

[5] Lotti T, Chimenti S, Katsambas A, et al. Efficacy and safety of efalizumab in patients with moderate-to-severe plaque psoriasis resistant to previous anti-psoriatic treatment: results of a multicentre, open-label, phase IIIb/IV trial. Arch Drug Inf 2010; 3 : $9-18$

[6] Gupta AK, Cherman AM. Efalizumab in the treatment of psoriasis. J Cutan Med Surg 2006; 10: 57-68.

[7] Rodríguez-Cerdeira C, Díez-Moreno S, Guerra-Tapia A, Vilata JJ. Efalizumab and psoriasis. Our experience. Poster presentation of $5^{\mathrm{t}}$ EADV Spring Symposium. Istanbul, 22-25 May, 2008.

[8] Díez-Moreno S, Rodriguez-Cerdeira C, Guerra-Tapia A, Vilata JJ. Poster presentation of IV Symposium of Psicodermatology. Zaragoza, 22-23 February, 2008

[9] Díez-Moreno S, Rodríguez-Cerdeira C, Guerra-Tapia A, Vilata JJ. Tratamiento de la psoriasis moderada y grave con Efalizumab: nuestra experiencia. Poster presentation of XXXVI Symposium of Dermatology and Venereology. Barcelona, 11 - 24 May, 2008.

(C) Rodríguez-Cerdeira et al.; Licensee Bentham Open.

This is an open access article licensed under the terms of the Creative Commons Attribution Non-Commercial License (http://creativecommons.org/licenses/by-nc/ $3.0 /$ ) which permits unrestricted, non-commercial use, distribution and reproduction in any medium, provided the work is properly cited. 